Article

\title{
Formation of Quasicrystalline Phases and Their Close Approximants in Cast Al-Mn Base Alloys Modified by Transition Metals
}

\author{
Katarzyna Stan-Głowińska
}

Institute of Metallurgy and Materials Science, Polish Academy of Sciences, Reymonta 25, 30-059 Kraków, Poland; k.stan@imim.pl

Received: 31 December 2017; Accepted: 22 January 2018; Published: 27 January 2018

\begin{abstract}
The aim of the presented research was to study the influence of $\mathrm{Cr}, \mathrm{Co}, \mathrm{Ni}$, and $\mathrm{Cu}$ additions on the formation of quasicrystalline particles in the $94 \mathrm{Al}-6 \mathrm{Mn}$ base alloy during casting at intermediate cooling rates. Based on the obtained results, $\mathrm{Cu}$ and $\mathrm{Ni}$ enhance quasicrystalline phase nucleation compared to the unmodified binary composition. In the case of $\mathrm{Cu}$ addition, formation of a quasicrystalline phase takes place along whole thickness of the prepared casting, but its fraction and morphology depends on the cooling rates present in different parts of the sample. Based on the previous works on the beneficial effect of Fe addition, a quaternary alloy containing both Fe and $\mathrm{Cu}$ was prepared to evaluate the effect of the simultaneous presence of these elements on the microstructure of the obtained castings.
\end{abstract}

Keywords: quasicrystals; approximants; TEM

\section{Introduction}

Development of aluminum alloys constantly inclines towards the improvement of their strength at room and elevated temperatures. Among different approaches, those connected with the developing microstructure containing quasicrystalline phases, or their close approximates, give promising results [1-4]. The first studies indicating the effectiveness of quasicrystals as a strengthening phase in aluminum alloys were performed in the early 1990s. It has been shown that nanosized primary metastable (I-phase) icosahedral particles formed by rapid solidification in the microstructure of transition metal-modified $\mathrm{Al}$ alloys result in high strength of prepared samples (above $600 \mathrm{MPa}$ ) [1,2]. This has been confirmed by some recent research [3-5]. Another approach also developed in the 1990s [6] considered the production of composite materials where stable quasicrystals were mixed with pure Al powder and subsequently consolidated $[7,8]$. As expected, the resulting material exhibited high hardness. Nevertheless, the first mentioned approach provides higher strength compared to the composite materials. This is connected with the size and distribution of fine I-phase particles in the microstructure and, at least partially, the coherent particle/matrix interface confirmed by the presence of crystallographic relations between the two phases [9-11]. The main drawback of the rapid solidification technique are high cooling rates above $10^{4} \mathrm{~K} / \mathrm{s}$ necessary for I-phase formation, which limit at least one size of a sample to tens of microns and, consequently, lead to additional processing steps in order to obtain bulk forms.

Although consolidated materials exhibit superior properties compared to commercially-used equivalents [12-14], application of quasicrystalline-strengthened alloys in the industry would be more feasible if the formation of such material was provided by common industrial processes. One such process is die casting, the technique used to produce thin-wall aluminum products (with a thickness of $1-1.5 \mathrm{~mm}$ ). This, however, implies formation of a quasicrystalline-strengthened microstructure using less severe cooling conditions (in the range from 50 to $500 \mathrm{~K} / \mathrm{s}$ [15]) than these achievable in 
rapid solidification methods. For many years it was believed that a fine two-phase microstructure composed of I-phase and $\mathrm{Al}$ can be formed only by rapid solidification techniques. However, it has been shown that Be addition strongly enhances I-phase nucleation in the Al-Mn alloys providing quasicrystals containing microstructures at considerable lower cooling rates [16-20]. Be addition is also known for being carcinogenic and causing other serious diseases, such as berylliosis [21], thus, other elements that could enhance the I-phase formation during conventional casting processes are desirable. Additionally, cerium-previously reported as promoting I-phase formation under different solidification conditions [22,23] —was recently disputed by Coury et al. [24]. Some other works show that in aluminum alloys alloyed with $\mathrm{Mn}, \mathrm{Cu}, \mathrm{Mg}$, and $\mathrm{Si}$, primary I-phase particles with petal morphology can be formed at low cooling rates [25]. Recently we have shown enhanced I-phase formability in the 94Al-6Mn alloy modified by various Fe additions obtained by different casting techniques [26,27]. In Fe-modified alloys, microstructures containing fine eutectic structures or larger (a few microns in size) petal icosahedral particles were developed when cooling rates of the order of $10^{3} \mathrm{~K} / \mathrm{s}$ were applied. According to our previous results, the highest hardness was obtained for a sample in which a fine $\mathrm{Al} / \mathrm{I}$-phase eutectic structure was formed. The highest fraction of fine I-phase particles was observed for samples with 2 at.\% addition of Fe. Thus, in further studies, similar amounts of the third alloying addition were used.

This work evaluates the effect of additions of different transition metals $(\mathrm{Cr}, \mathrm{Co}, \mathrm{Ni}$, and $\mathrm{Cu})$ on the formation of a quasicrystalline phase in the Al-Mn alloy cast at intermediate cooling rates $\left(10^{3}-10 \mathrm{~K} / \mathrm{s}\right)$ obtained by simple gravity casting into a wedge-shaped copper mold.

\section{Materials and Methods}

Ternary alloys of the following nominal compositions (at.\%): 94Al-4Mn-2Cr, 94Al-4Mn-2Co, 94Al-4Mn-2Ni, $94 \mathrm{Al}-4 \mathrm{Mn}-2 \mathrm{Cu}$ were prepared by melting a mixture of pure elements ( $\mathrm{Al}$ 99.99, Mn 99.99, Cr 99.99, Co. 99.99, Ni 99.99, Cu 99.99, Fe 99.99) in a resistant furnace under an argon atmosphere. The samples were subsequently cast into a steel mold $20 \times 30 \times 60 \mathrm{~mm}$. The resulting chemical compositions were confirmed by energy-dispersive X-ray spectroscopy (EDS) in a scanning electron microscope (SEM) and are given in Table 1. Four measurements for each alloy were performed using an accelerating voltage of $20 \mathrm{kV}$.

Table 1. Average chemical compositions in at.\% (where $\mathrm{X}=\mathrm{Cr}$, Co., $\mathrm{Ni}$, or $\mathrm{Cu}$ ) measured by EDS in SEM together with the relative error given.

\begin{tabular}{cccc}
\hline \multirow{2}{*}{ Alloy Designation } & \multicolumn{3}{c}{ Composition (at.\%) } \\
\cline { 2 - 4 } & Al & Mn & X \\
\hline 94Al-4Mn-2Cr & $93.7 \pm 1.9$ & $4.2 \pm 0.4$ & $2.1 \pm 0.4$ \\
94Al-4Mn-2Co & $93.5 \pm 1.9$ & $4.5 \pm 0.5$ & $2.0 \pm 0.4$ \\
94Al-4Mn-2Ni & $93.7 \pm 1.9$ & $3.9 \pm 0.4$ & $2.4 \pm 0.5$ \\
94Al-4Mn-2Cu & $93.1 \pm 1.9$ & $4.3 \pm 0.4$ & $2.6 \pm 0.5$ \\
\hline
\end{tabular}

Additionally, a quaternary alloy with a nominal composition (at.\%): 94Al-4Mn-1Fe-1Cu was prepared. The average composition of the quaternary sample measured by EDS was Al-92.9 \pm 1.9 , $\mathrm{Mn}-4.4 \pm 0.4, \mathrm{Fe}-1.3 \pm 0.3$ and $\mathrm{Cu}-1.4 \pm 0.3$ at. $\%$

The prepared ingots were cut into pieces, re-melted (at $1300 \mathrm{~K}$ ), and gravitationally cast into a wedge-shaped copper mold (Figure 1a). Calibration of the cooling rates was conducted by analyzing a microstructure of a reference $98 \mathrm{Al}-2 \mathrm{Cu}$ at.\% alloy, which has been presented in [27]. An example of the obtained casting is shown schematically in Figure $1 \mathrm{~b}$. The analyzed cross-section has been divided into separate zones. The selected zones are characterized by increasing thickness and consequently decreasing cooling rates. Additionally, thin rods ( $1 \mathrm{~mm}$ in diameter) were prepared by suction casting for Vickers hardness (HV) tests using a CSM Instruments microhardness tester (Needham, MA, USA) and a load of $10 \mathrm{~N}$. The HV values were determined based on the F/A ratio where F is the force applied 
to the indenter and $\mathrm{A}$ is the surface area of the resulting indentation calculated based on the average length of the diagonal left by the indenter.

a)

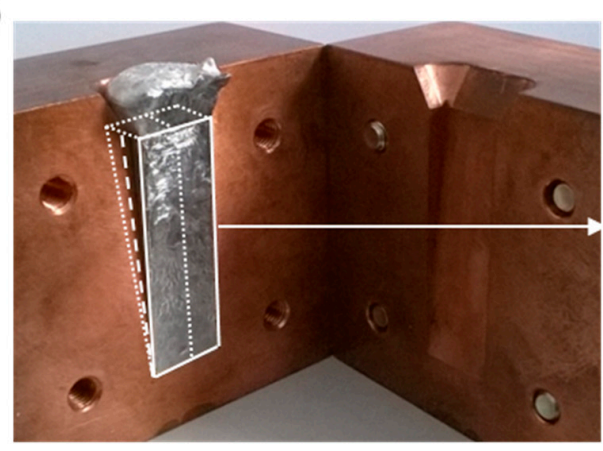

b)

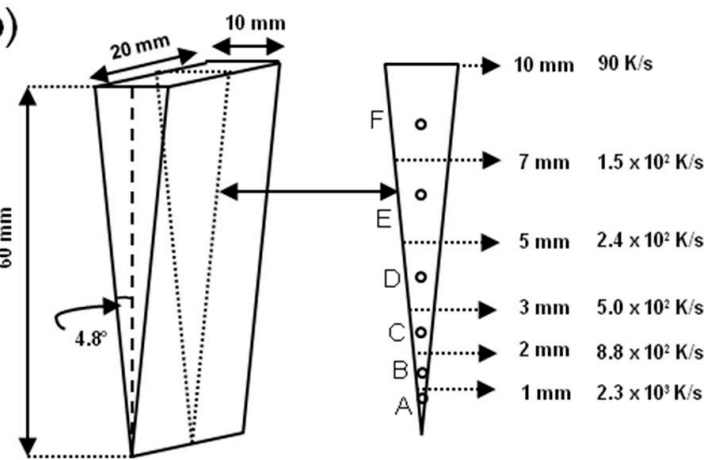

Figure 1. (a) The mold used in the experiments with an example of the obtained casting and (b) a schematic of the mold cavity and its cross-section which has been divided into separate zones. Examples of cooling rates for the specific sample thickness are given.

The obtained castings were examined using scanning electron microscope E-SEM XL30 (FEI/Philips, Hillsboro, OR, USA) and transmission electron microscope Tecnai SuperTWIN G2 (TEM) (FEI, Hillsboro, OR, USA) operating at $200 \mathrm{keV}$ equipped with a field-emission gun (FEG) (FEI, Hillsboro, OR, USA) and high-angle annular dark field scanning transmission electron microscopy detector (HAADF-STEM) (Gatan, Pleasanton, CA, USA). Preparation of the thin foils was done using Tenupol-5 double jet electropolisher (Struers, Willich, Germany) and an electrolyte containing nitric acid and methanol (1:3) at the temperature of $243 \mathrm{~K}$ and voltage of $15 \mathrm{~V}$.

\section{Results and Discussion}

In the presented experiment cooling rates $\sim 500 \mathrm{~K} / \mathrm{s}$ (upper limit of cooling rates for die casting process) can be achieved at a wedge thickness around $3 \mathrm{~mm}$ (zone $C$ and D); thus, the work will focus on the microstructure changes between zones A, B, C, and D shown in Figure 1b. Analysis of the microstructure in the thinnest area (zone $\mathrm{A}$ - up to $1 \mathrm{~mm}$ thickness), characterized by the highest cooling rates-the mean value for whole zone $\sim 4 \times 10^{3} \mathrm{~K} / \mathrm{s}$ - show substantial differences between alloys depending on the alloying element used.

\subsection{Samples with $\mathrm{Cr}$ and Co Addition}

In Figure 2, the micrographs represent a microstructure observed in the central part of Co- and $\mathrm{Cr}$-modified castings. The $\mathrm{Cr}$-containing alloy exhibits a more homogeneous microstructure (Figure 2a) while, in the alloy with Co addition, larger particles surrounded by a fine eutectic structure are visible (Figure 2b).
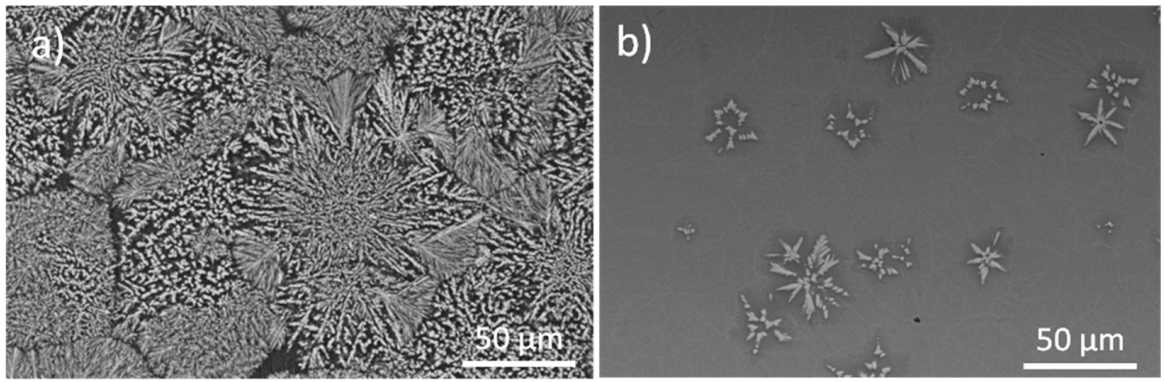

Figure 2. SEM micrographs (BSE mode) revealing the microstructure of the zone A (as shown in Figure 1 b) in the (a) Cr-; and (b) Co-modified Al-Mn alloy. 
The microstructure of the $94 \mathrm{Al}-4 \mathrm{Mn}-2 \mathrm{Cr}$ sample observed in the zone A consists of a mixture of different crystalline phases. The dominant phase observed was identified as an orthorhombic L-phase with lattice parameters $\mathrm{a}=12.4, \mathrm{~b}=12.6, \mathrm{c}=30.5 \AA$, which has also been found in the binary $94 \mathrm{Al}-6 \mathrm{Mn}$ sample in the same zone studied in the previous works [26,27]. This phase occurs in the form of plate-like particles (Figure 3a). Additionally, a monoclinic $\mathrm{Al}_{45} \mathrm{Cr}_{7}$ phase $(\mathrm{a}=20.8, \mathrm{~b}=7.6, \mathrm{c}=11.1 \AA$, $\left.\beta=107^{\circ}\right)$ visible in Figure $3 \mathrm{~b}$, and some traces of cubic $\mathrm{Al}_{12}(\mathrm{Mn}, \mathrm{Cr})$ phase $(\mathrm{a}=7.5 \AA)$ were detected. Zone A of the $94 \mathrm{Al}-4 \mathrm{Mn}-2 \mathrm{Co}$ casting consisted of fine intergranular particles of a monoclinic $\mathrm{Al}_{9}(\mathrm{Mn}$, $\mathrm{Co})_{2}$ phase $\left(\mathrm{a}=6.2, \mathrm{~b}=6.3, \mathrm{c}=8.6 \AA, \beta=94.8^{\circ}\right)$, and larger primary particles with a hexagonal structure $\mathrm{a}=12.4, \mathrm{c}=12.4 \AA$ [28] (phase-H) with stoichiometry close to $\mathrm{Al}_{4}(\mathrm{Mn}, \mathrm{Co}$ ) (Figure 3c). Even for the thinnest areas connected with the highest cooling rates, no traces of quasicrystalline phases in the case of alloys with $\mathrm{Cr}$ and $\mathrm{Co}$ additions were found. Due to a lack of a quasicrystalline phase in zone A, further zones were not described here in detail. For these two samples, coarsening of the identified intermetallic phases with increasing thickness was observed.
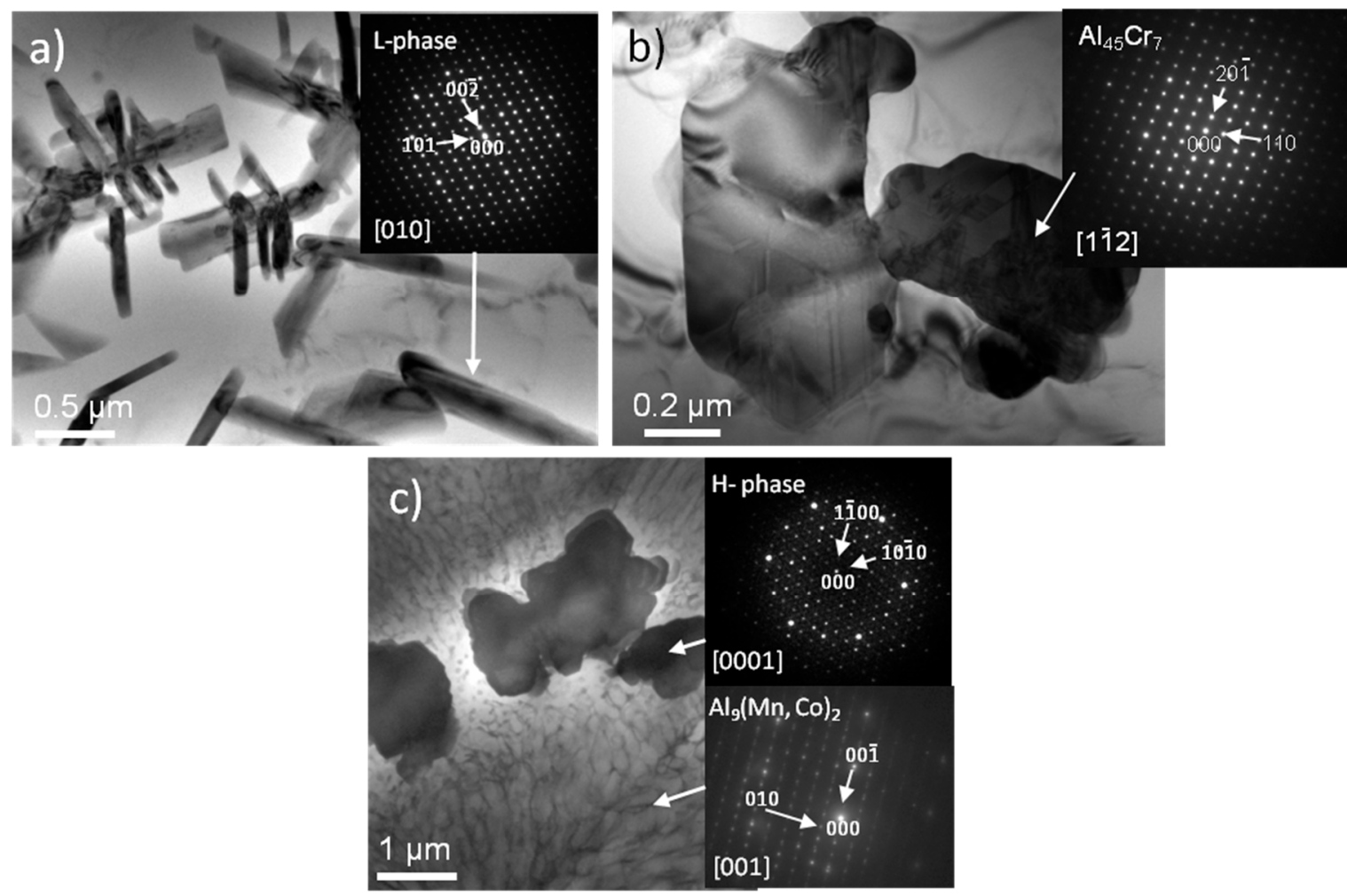

Figure 3. TEM bright-field images of microstructures observed in zone A of Al-Mn alloys modified by $(\mathbf{a}, \mathbf{b}) \mathrm{Cr}$; and (c) Co. Insets in each micrograph present electron diffraction patterns taken from phases marked by arrows.

\subsection{Sample with Ni Addition}

The microstructures of various zones for the Ni-modified sample are gathered in Figure 4 . The first one (Figure 4a) shows some similarities to that observed in the sample with Co addition. It contains a flower-like primary phase surrounded by fine intergranular particles. The detailed analysis using TEM revealed a cellular structure consisting of aluminum grains surrounded by a mixture of a crystalline monoclinic $\mathrm{Al}_{9}(\mathrm{Mn}, \mathrm{Ni})_{2}$ phase and a nano-quasicrystalline phase of icosahedral type-I-phase (Figure 5). The larger flower like-particles occasionally occurring in the first zone were also observed in further zones, and were identified as a close approximate of a decagonal phase-orthorhombic O-phase with lattice parameters $\mathrm{a}=12.4, \mathrm{~b}=24.0, \mathrm{c}=32.7 \AA$. This phase was previously reported to form in Al-Mn-Ni alloys [29]. 

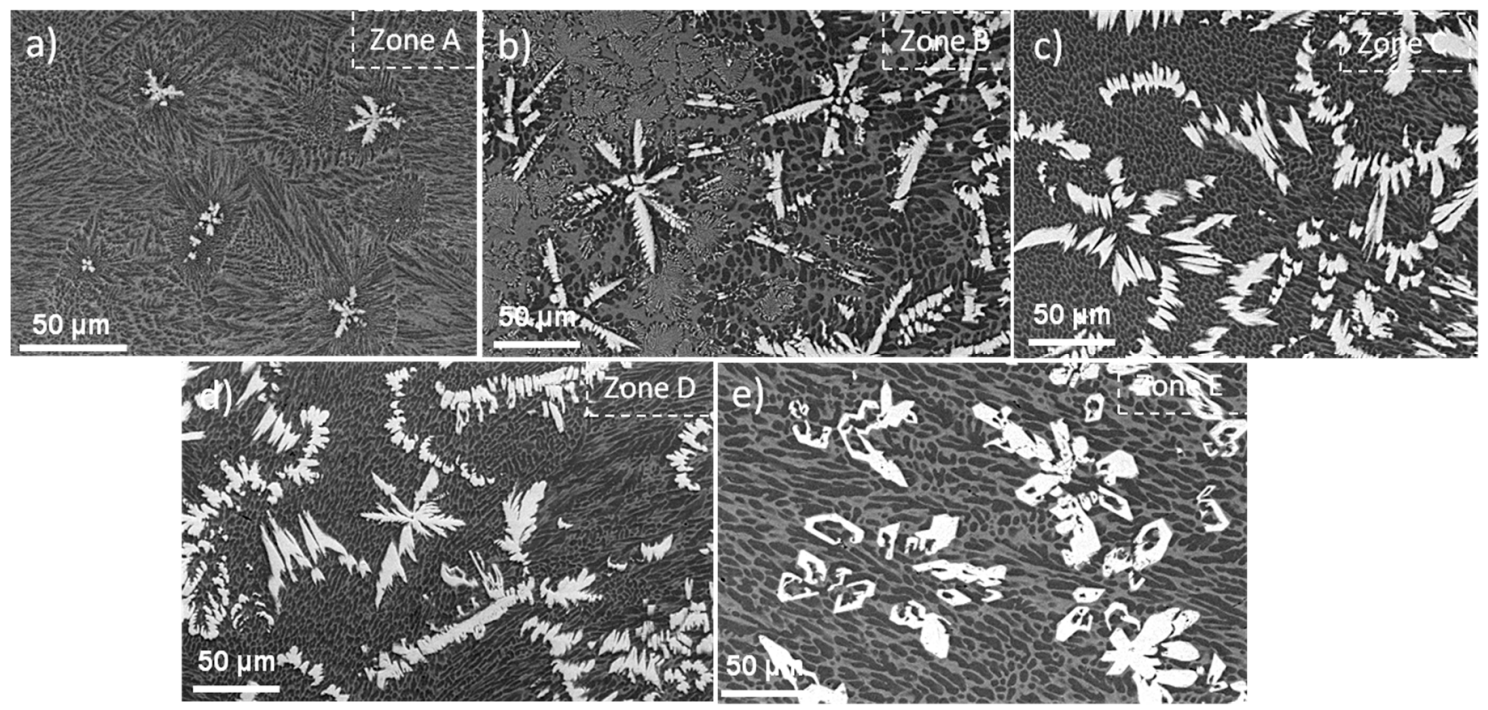

Figure 4. SEM micrographs (BSE mode) revealing the microstructure of (a) zone A; (b) zone B; (c) zone $\mathrm{C}$; (d) zone $\mathrm{D}$; and (e) zone $\mathrm{E}$ of Ni-containing Al-Mn alloy.

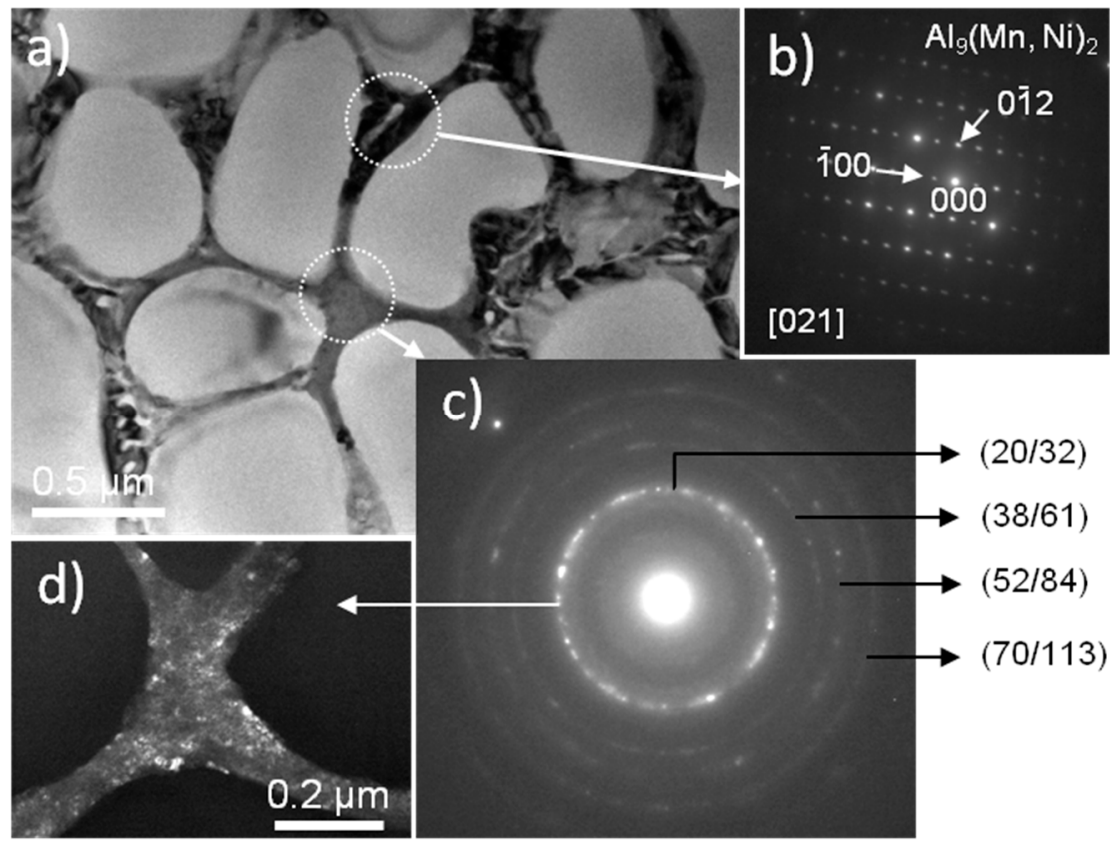

Figure 5. (a) A TEM bright-field image of the microstructure observed in zone A of the $94 \mathrm{Al}-4 \mathrm{Mn}-2 \mathrm{Ni}$ alloy. Insets $(\mathbf{b}, \mathbf{c})$ present electron diffraction patterns taken from phases marked by arrows. Additionally, a dark-field image taken from the (20/32) reflection corresponding to an icosahedral quasicrystalline phase was given (d).

The further zones, especially zone B and $\mathrm{C}$ in the $94 \mathrm{Al}-4 \mathrm{Mn}-2 \mathrm{Ni}$ alloy, besides the monoclinic $\mathrm{Al}_{9}(\mathrm{Mn}, \mathrm{Ni})_{2}$ and the orthorhombic O-phase, also contain a hexagonal phase observed previously in the sample with Co addition $(\mathrm{a}=12.4, \mathrm{c}=12.4 \AA$ [29] $)$ and some traces of a quasicrystalline phase of a decagonal type-D-phase (Figure 6).

The thicker zones D, E, and F mainly contain two phases: a hexagonal phase marked as $\mathrm{K}-\mathrm{a}=17.6$, c $=12.5 \AA$ phase, and the O-phase mentioned earlier (Figure 7). 


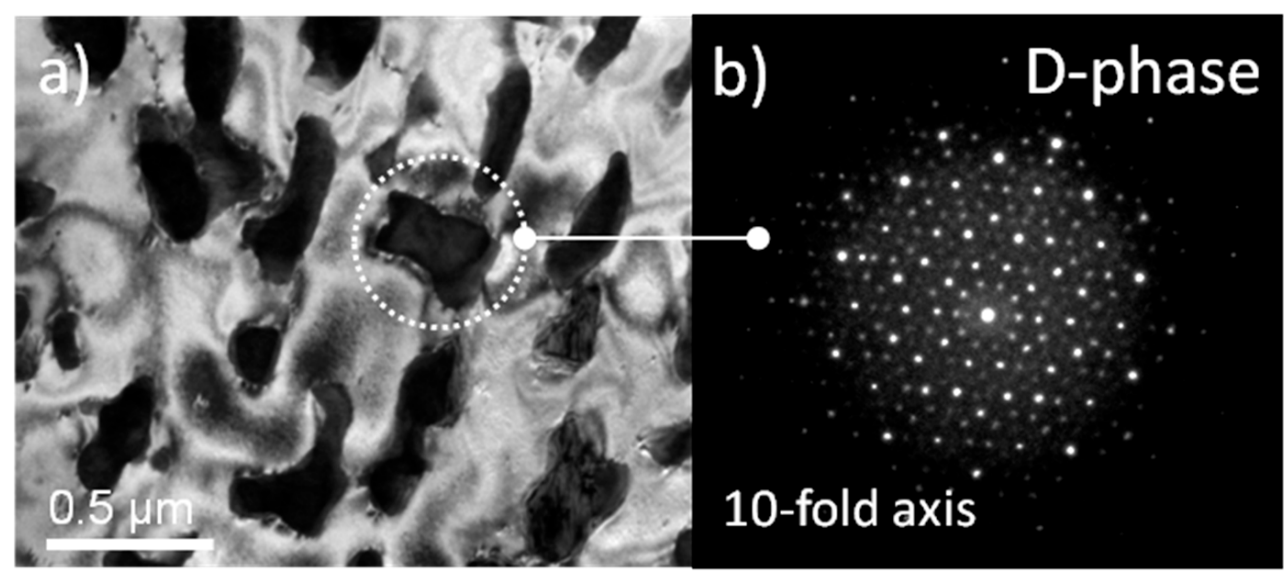

Figure 6. (a) A TEM bright-field micrograph showing a part of the microstructure in zone $C$ in the 94Al-4Mn-2Ni alloy containing particles of a D-phase identified by (b) electron diffraction patterns.

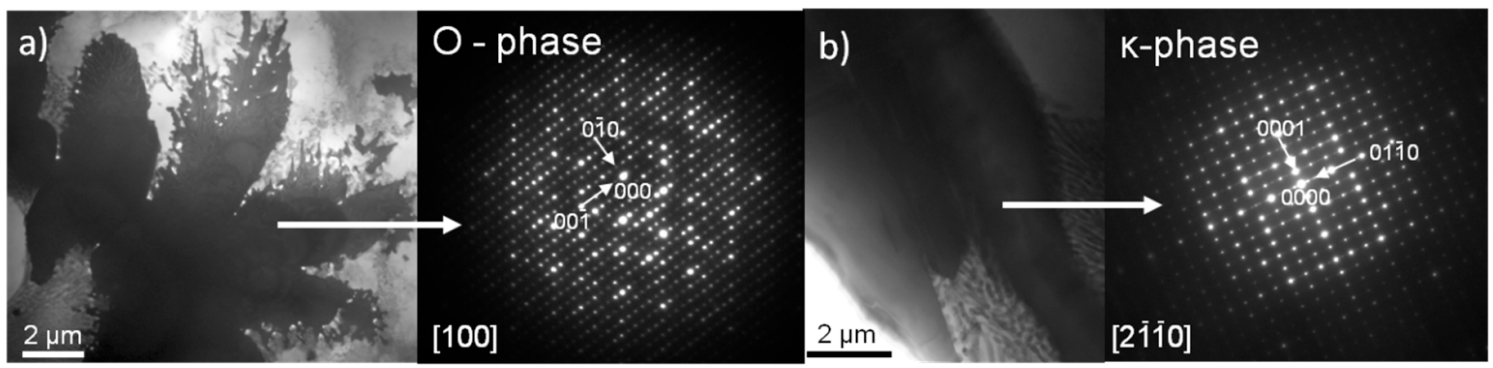

Figure 7. A TEM bright-field images showing phases observed in zones C, D, and E in the $94 \mathrm{Al}-4 \mathrm{Mn}-2 \mathrm{Ni}$ alloy (a) the O-phase; and (b) the $\mathrm{k}$-phase being a close approximate of a decagonal phase.

\subsection{Sample with $\mathrm{Cu}$ Addition}

The microstructures found in different zones of the alloy with $\mathrm{Cu}$ addition are given in Figures 8 and 9. Zone A contains a cellular structure composed of aluminum cells surrounded by an intergranular decagonal phase. The chemical analysis performed in selected areas using EDS revealed a heterogeneous distribution of $\mathrm{Cu}$ and $\mathrm{Mn}$ in the intergranular regions. Two regions can be distinguished: the region containing the quasicrystalline decagonal phase particles enriched in $\mathrm{Al}$, $\mathrm{Cu}$, and $\mathrm{Mn}(\mathrm{Al}-77, \mathrm{Mn}-13, \mathrm{Cu}-10$ at.\%) and the regions enriched mainly in $\mathrm{Al}$ and $\mathrm{Cu}$ (Al-74, Mn-1, $\mathrm{Cu}-25$ at.\%) as indicated by the arrows in Figure 8e,f. The differences in $\mathrm{Cu}$ distributions suggest the formation of a second phase with stoichiometry close to $\mathrm{Al}_{3} \mathrm{Cu}$. The thicker parts of the casting were also found to contain a decagonal phase in the form of primary particles with a petal morphology (Figures 9 and 10). Based on the recorded electron diffraction patterns and the position of the main diffraction points (see Figure $10 \mathrm{~b}$ and the inset showing the magnified area) their structure is slightly distorted and their composition (Al-82, Mn-15, Cu-3 at.\%) differs from the intergranular D-phase. 

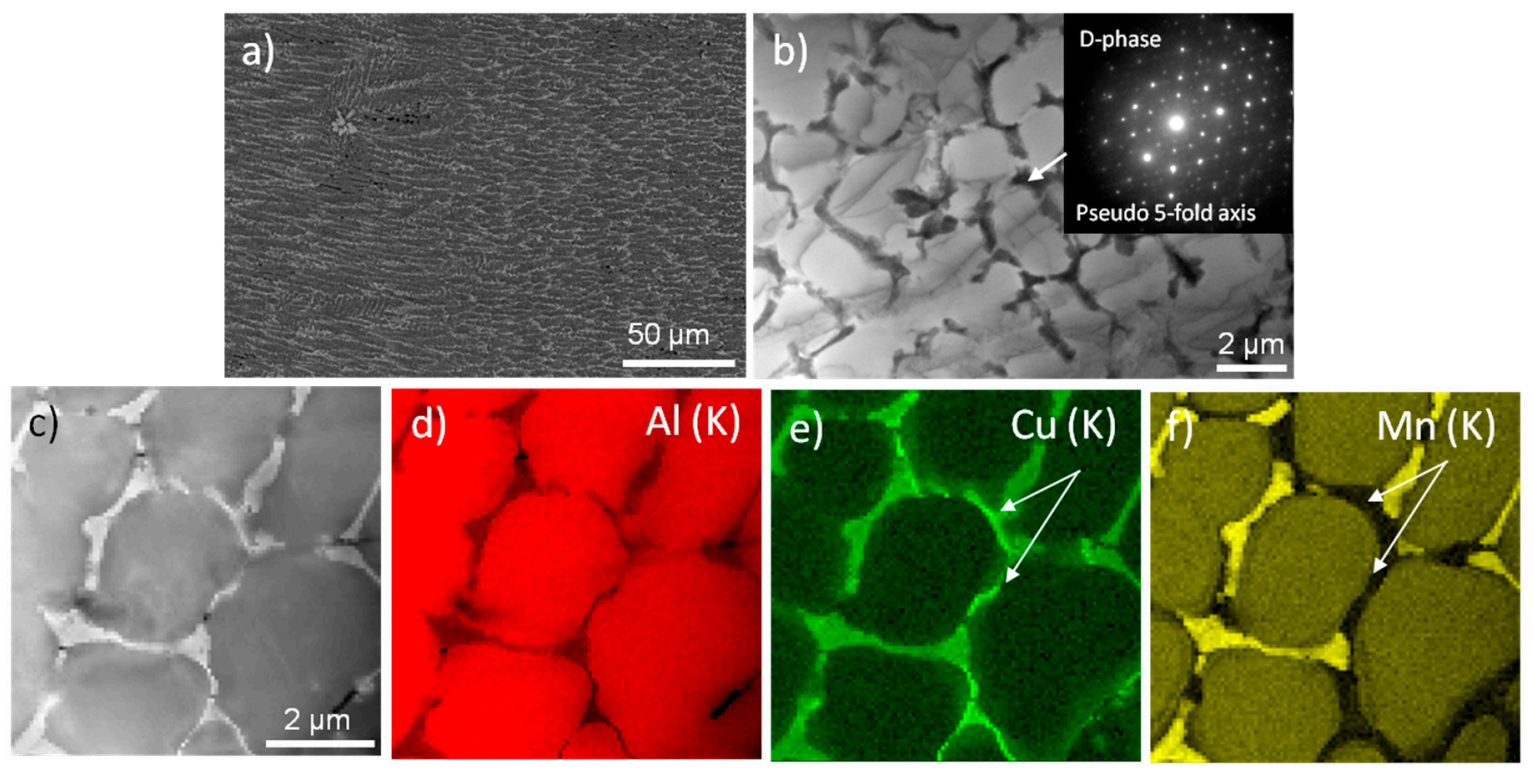

Figure 8. (a) A SEM (BSE) microstructure of zone A in the 94Al-4Mn-2Cu wedge-casting; (b) a TEM bright-field image of zone A with inset of an electron diffraction pattern taken from the D-phase marked by the arrow; and (c) a HAADF STEM image with $(\mathbf{d}-\mathbf{f})$ a distribution of particular elements in the microstructure of zone A showing heterogeneities of $\mathrm{Mn}$ in the intergranular areas.
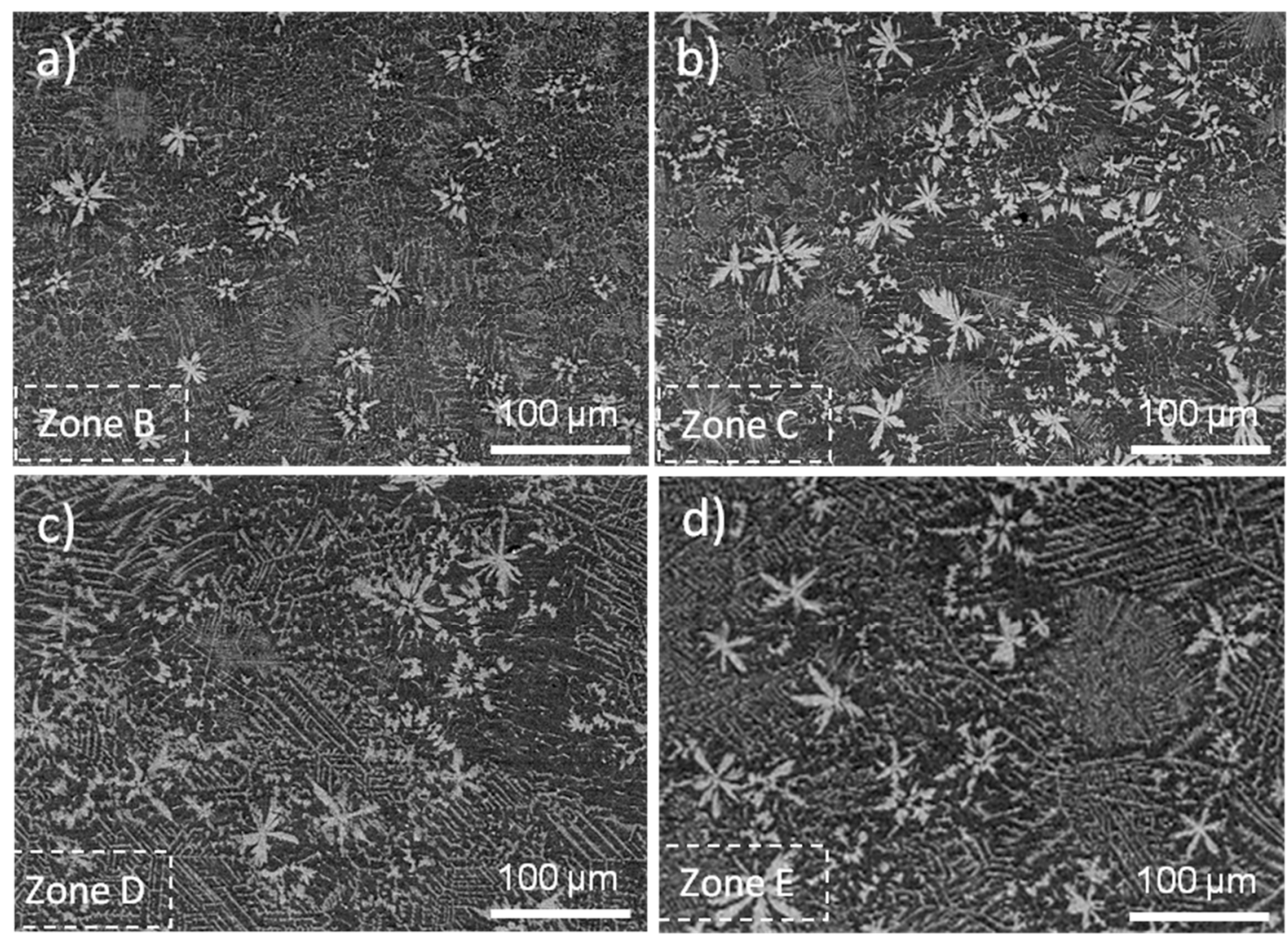

Figure 9. (a-d) SEM microstructures (recorded in the BSE mode) of the 94Al-4Mn-2Cu wedge-casting at different thicknesses (zones). 

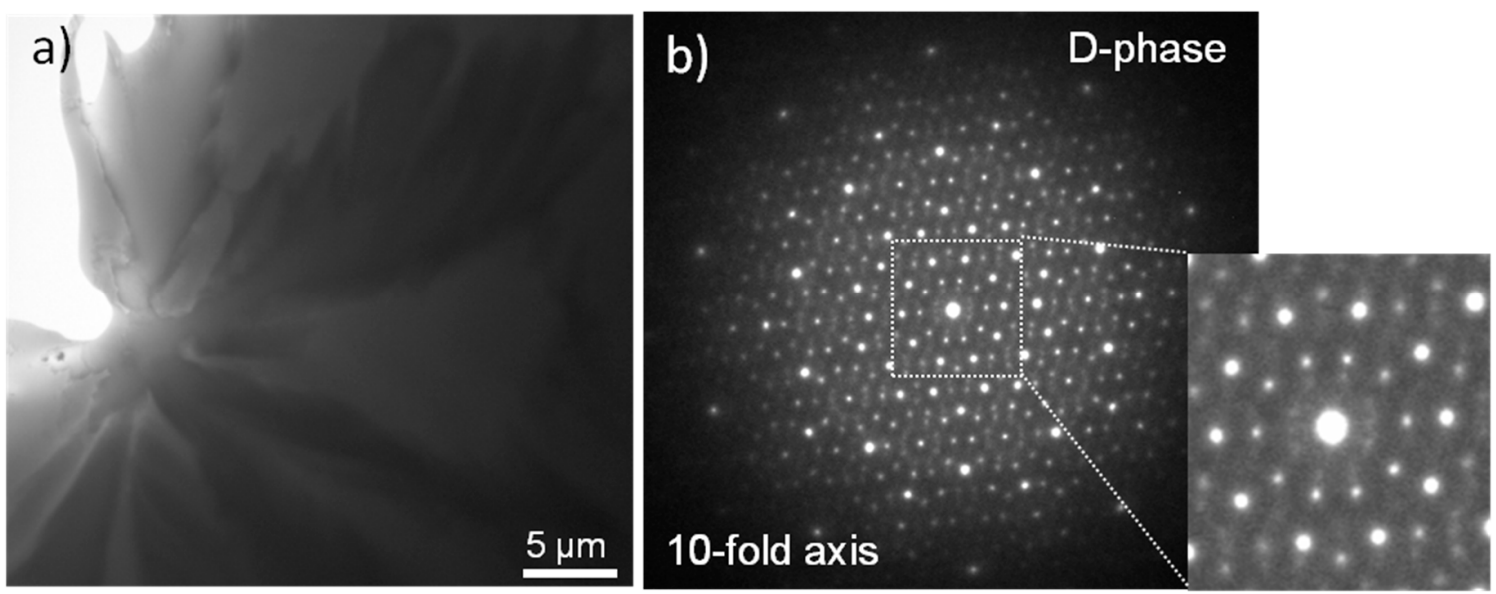

Figure 10. (a) A TEM bright-field image showing a dendritic particle identified as a decagonal phase in the $94 \mathrm{Al}-4 \mathrm{Mn}-2 \mathrm{Cu}$ alloy; and (b) an electron diffraction pattern from the D-phase.

In zone $\mathrm{B}$, a decagonal phase was found to coexist with its close approximate, the orthorhombic O-phase (Figure 11a). In the thicker zones (Figure 11b,c) adjacent to the decagonal phase various crystalline phases occur (Figure 11) including a needle-like orthorhombic $\mathrm{L}(\mathrm{a}=12.4, \mathrm{~b}=12.6, \mathrm{c}=30.5 \AA)$ and $R$ phase $(a=24.1, b=12.5, c=7.6 \AA)$ [30], an orthorhombic $\mathrm{Al}_{6} \mathrm{Mn}(\mathrm{a}=7.6, \mathrm{~b}=6.5, \mathrm{c}=8.9 \AA)$, and $\mathrm{a}$ tetragonal $\mathrm{Al}_{2} \mathrm{Cu}$ phase $(\mathrm{a}=\mathrm{b}=6.1, \mathrm{c}=4.9 \AA)$.
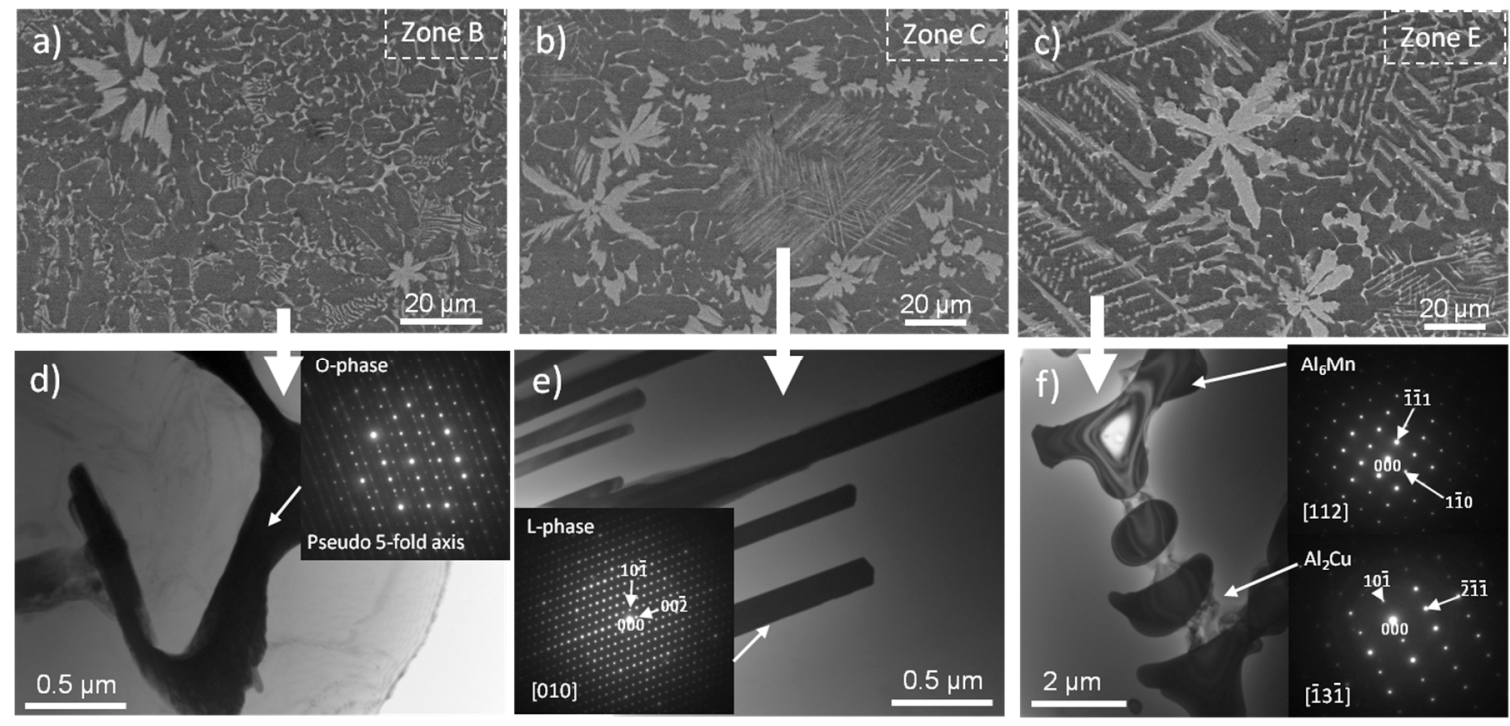

Figure 11. (a-c) SEM (BSE) micrographs showing microstructures observed in zone B, C, and D of the 94Al-4Mn-2Cu alloy, (d-f) TEM bright-field images together with electron diffraction patterns showing different phases observed in the vicinity of primary decagonal particles in the $94 \mathrm{Al}-4 \mathrm{Mn}-2 \mathrm{Cu}$ alloy: (d) the intergranular O-phase in zone B; (e) needles of the L-phase in zone C; and (f) $\mathrm{Al}_{6} \mathrm{Mn}$ and $\mathrm{Al}_{2} \mathrm{Cu}$ phases in zone E.

To compare properties of the selected alloys, hardness tests on the 1-mm rods were performed. The microstructure of 1-mm rods is essentially similar to that observed in the first zone of the wedge-shape castings [26]. This zone contains the finest and most homogenously-distributed particles. Formation of a quasicrystalline decagonal and icosahedral phase was also the most evident for this area, thus, it gives an opportunity to compare the hardness depending on the phase composition of different alloys (Table 2). Higher hardness values are obtained for samples modified by $\mathrm{Cu}, \mathrm{Ni}$, 
and Fe containing fine particles of a decagonal phase $(\mathrm{Cu})$, a close approximate of the decagonal phase $(\mathrm{Ni})$ and an icosahedral phase (Fe). Based on the microstructure analysis, $\mathrm{Cu}$ addition also promotes nucleation of a quasicrystalline decagonal phase at low cooling rates. Based on the previous studies, Fe enhances nucleation of icosahedral quasicrystalline particles in Al-Mn alloys at intermediate cooling rates $[26,27]$.

Thus, the effect of both $\mathrm{Fe}$ and $\mathrm{Cu}$ additions on the microstructure of quaternary castings (designated as 94Al-4Mn-1Fe-1Cu) was studied. In the first zone the microstructure of the obtained sample was similar to that observed in the ternary 94Al-4Mn-2Fe wedge-shaped ingot [27]. A fine eutectic, cellular structure and larger primary particles with a petal morphology were formed (Figure 12).

Table 2. Phase compositions of alloys in zone A of wedge ingots and Vickers hardness values (HV) for a $1 \mathrm{~mm}$ rod showing a similar microstructure. Data for the $94 \mathrm{Al}-6 \mathrm{Mn}$ and $94 \mathrm{Al}-4 \mathrm{Mn}-2 \mathrm{Fe}$ are taken from $[26,27]$.

\begin{tabular}{ccc}
\hline Alloy Designation & Phase Composition for Zone A (up to 1 mm Thickness) & HV (1 mm Rod) \\
\hline $94 \mathrm{Al}-6 \mathrm{Mn}$ & $\mathrm{Al}, \mathrm{L}-\mathrm{phase}$ & $116 \pm 16$ \\
$94 \mathrm{Al}-4 \mathrm{Mn}-2 \mathrm{Cr}$ & $\mathrm{Al}, \mathrm{L}-\mathrm{phase}, \mathrm{Al}_{45} \mathrm{Cr}_{7}, \mathrm{Al}_{12}(\mathrm{Mn}, \mathrm{Cr})$ & $130 \pm 16$ \\
$94 \mathrm{Al}-4 \mathrm{Mn}-2 \mathrm{Co}$ & $\mathrm{Al}, \mathrm{Al}_{9}(\mathrm{Mn}, \mathrm{Ni})_{2}, \mathrm{H}-$ phase & $107 \pm 5$ \\
$94 \mathrm{Al}-4 \mathrm{Mn}-2 \mathrm{Ni}$ & $\mathrm{Al}, \mathrm{Al}_{9}(\mathrm{Mn}, \mathrm{Ni})_{2}, \mathrm{O}-$ phase, nano-I-phase & $147 \pm 3$ \\
$94 \mathrm{Al}-4 \mathrm{Mn}-2 \mathrm{Cu}$ & $\mathrm{Al}, \mathrm{D}-$ phase & $134 \pm 10$ \\
$94 \mathrm{Al}-4 \mathrm{Mn}-2 \mathrm{Fe}$ & $\mathrm{Al}, \mathrm{I}-$ phase & $154 \pm 8$ \\
\hline
\end{tabular}
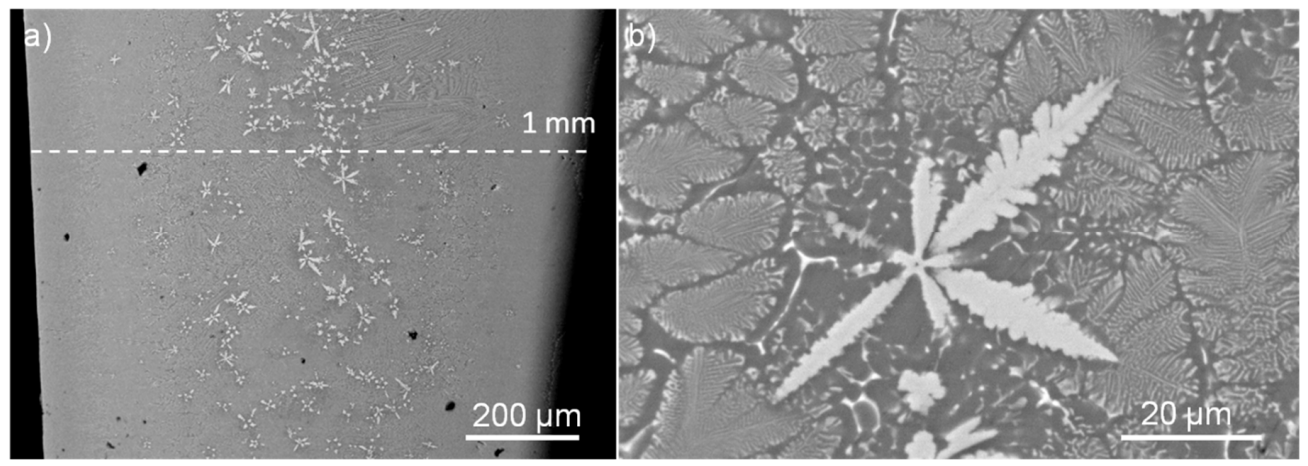

Figure 12. (a,b) SEM microstructures (recorded in BSE mode) of the $94 \mathrm{Al}-4 \mathrm{Mn}-1 \mathrm{Fe}-1 \mathrm{Cu}$ wedge-casting.

The detailed analysis of the regions with a fine microstructure using TEM revealed that cellular and eutectic particles show quasicrystalline structure of an icosahedral type (Figure 13).

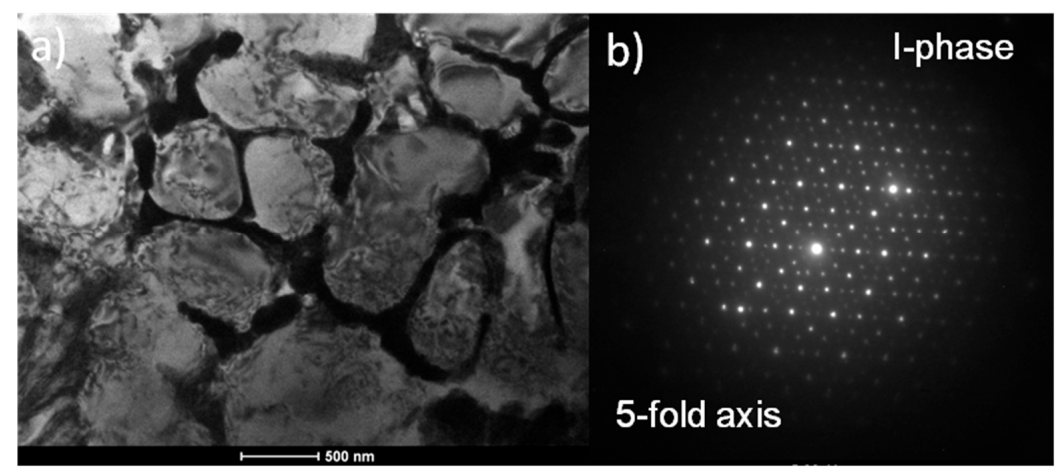

Figure 13. (a) A TEM bright-field microstructure of zone A in the $94 \mathrm{Al}-4 \mathrm{Mn}-1 \mathrm{Fe}-1 \mathrm{Cu}$ wedge-casting; and (b) a selected area electron diffraction pattern taken from one of intergranular particles showing five-fold symmetry typical for an icosahedral quasicrystalline phase. 
Both types of structures are enriched in $\mathrm{Fe}$ and $\mathrm{Cu}$ (Figure 14). The distribution of the latter is more homogeneous than in the case of the ternary $94 \mathrm{Al}-4 \mathrm{Mn}-2 \mathrm{Cu}$ alloy. Although both elements take part in the formation of the I-phase, the thickness of the casting at which the two-phase microstructure formed was similar to that obtained in the case of the ternary $94 \mathrm{Al}-4 \mathrm{Mn}-2 \mathrm{Fe}$ alloy.

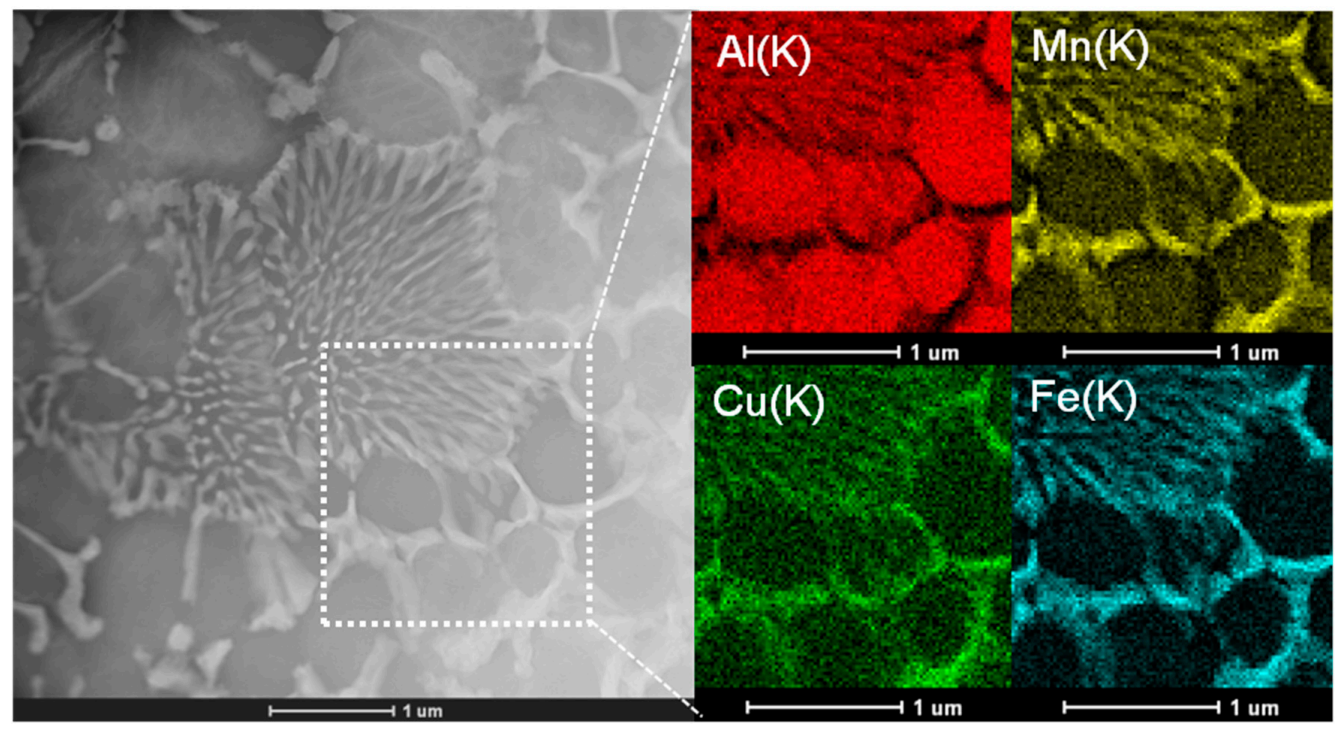

Figure 14. A HAADF-STEM image of the microstructure of zone A in the $94 \mathrm{Al}-4 \mathrm{Mn}-1 \mathrm{Fe}-1 \mathrm{Cu}$ wedge-casting.

\section{Summary}

Based on the presented results quasicrystalline phases can be obtained in Al-Mn alloys modified by $\mathrm{Cu}, \mathrm{Ni}$, and $\mathrm{Fe}$ addition at intermediate cooling rates. The analysis of the microstructures of wedge castings, especially in the thinnest zone (up to $1 \mathrm{~mm}$ thickness) characterized by cooling rates $\sim 10^{3} \mathrm{~K} / \mathrm{s}$, indicated that $\mathrm{Cu}$ addition promotes a decagonal phase formation, while Fe enhances nucleation of an icosahedral phase. Some traces of fine particles of I- and D-phases were also observed in the case of the Ni-modified sample, while $\mathrm{Cr}$ and $\mathrm{Co}$ additions did not promote any quasicrystalline phase nucleation. To understand the influence of the added elements on this particular phase formation in the studied alloys one can refer to phase diagrams of adequate systems which cover a range of concentrations of constituent elements and, thus, give a wider overview of different nucleation and stabilization effects promoted by different transition metals. Although the diagrams which cover the compositions used in this work are not available in the literature, some recent studies of phase equilibrium in the Al-rich region containing the same transition metals can still be helpful. The studies revealed that a stable decagonal phase occurs in the ternary Al-Cr-Fe [31], Al-Mn-Fe [32], Al-Cu-Mn [33] system and a metastable one in the Al-Mn-Ni system [34]. The available diagrams clearly show that both Fe and $\mathrm{Cu}$ take part in the quasicrystalline phase nucleation and stabilization (for example, the I-phase was found to exist at equilibrium conditions in the Al-Cu-Fe system [35-37] and the D-phase was found in the recently-studied $\mathrm{Al}-\mathrm{Mn}-\mathrm{Fe}$ and $\mathrm{Al}-\mathrm{Cu}-\mathrm{Mn}$ systems). This is in agreement with results obtained in this work. The I-phase forms in alloys with Fe addition and the D-phase forms in alloy with $\mathrm{Cu}$ addition, while a combination of both elements in a quaternary alloy leads again to I-phase nucleation (based on chemical analysis I-phase is enriched in both elements).

However, it is important to note that in the available phase diagrams quasicrystalline phases coexist with various intermetallics, but not exclusively with Al. Our experiments show that, for the given alloy composition, a two-phase microstructure $\mathrm{Al}+\mathrm{I}$-phase can be formed in the sample at conditions that can be achieved by industrial casting processes. This, in turn, gives the studied alloys a new application potential. Although these two alloying elements clearly affect quasicrystalline phase nucleation also in Al-rich alloys obtained at intermediate cooling rates, optimization of a microstructure 
is still needed concerning the mechanical properties of the obtained samples. The size and morphology of the obtained phases varied in the studied alloys. A quasicrystalline phase was observed in the form of a fine cellular and eutectic structure, as well as in the form of primary particles with petal morphology. Formation of a hard brittle phase in the intergranular regions is undesirable due to its negative effect on sample ductility and fracture toughness. Additionally, large dendrites of primary particles are not optimum for the best material performance. Ideally, a fine I-phase/Al eutectic is desired. Such a structure can be obtained in Fe-modified samples, but in a very limited volume. For $\mathrm{Cu}$ addition, a quasicrystalline phase can be obtained in a higher volume, but mostly in the form of a brittle intergranular phase or primary large particles with petal morphology (a D-phase could be found up to a thickness of $7 \mathrm{~mm}$ of the resulting casting).

Acknowledgments: This work was financially supported by National Science Center Poland within the project no. 2012/07/N/ST8/03922. The author would like to thank L. Lityńska-Dobrzyńska for discussions and Ł. Rogal for his help with the casting processes.

Conflicts of Interest: The author declares no conflict of interest.

\section{References}

1. Inoue, A.; Kimura, H.; Sasamori, K.; Masumoto, T. High mechanical strength of Al-(V, Cr,Mn)-(Fe, Co-Ni) quasicrystalline alloys prepared by rapid solidification. Mater. Trans. JIM 1996, 37, 1287-1292. [CrossRef]

2. Inoue, A.; Kimura, H.; Yamaura, S. Production and mechanical properties of aluminum alloys with dispersed nanoscale quasicrystalline and amorphous particles. Met. Mater. Int. 2003, 9, 527-536. [CrossRef]

3. Galano, M.; Audebert, F.; Escorial, A.G.; Stone, I.C.; Cantor, B. Nanoquasicrystalline Al-Fe-Cr-based alloys. Part II. Mechanical properties. Acta Mater. 2009, 57, 5120-5130. [CrossRef]

4. Watson, T.J.; Gordillo, M.A.; Cernatescu, I.; Aindow, M. Structure and mechanical properties in a powderprocessed icosahedral-phase-strengthened aluminum alloy. Scr. Mater. 2016, 123, 51-54. [CrossRef]

5. Pedrazzini, S.; Galano, M.; Audebert, F.; Collins, D.M.; Hofmann, F.; Abbey, B.; Korsunsky, A.M.; Lieblich, M.; Escorial, A.G.; Smith, W.G.D. Strengthening mechanisms in an Al-Fe-Cr-Ti nano-quasicrystalline alloy and composites. Mater. Sci. Eng. A 2016, 672, 175-183. [CrossRef]

6. Tsai, A.P.; Aoki, K.; Inoue, A.; Masumoto, T. Synthesis of stable quasicrystalline particledispersed Al base composite alloys. J. Mater. Res. 1993, 8, 5-7. [CrossRef]

7. Kaloshkin, S.D.; Tcherdyntsev, V.V.; Laptev, A.I.; Stepashkin, A.A.; Afonina, E.A.; Pomadchik, A.L.; Bugakov, V.I. Structure and mechanical properties of mechanically alloyed Al/Al-Cu-Fe composites. J. Mater. Sci. 2004, 39, 5399-5402. [CrossRef]

8. Lityńska-Dobrzyńska, L.; Mitka, M.; Góral, A.; Stan-Głowińska, K.; Dutkiewicz, J. Microstructure and mechanical properties of aluminium matrix composites reinforced by $\mathrm{Al}_{62} \mathrm{Cu}_{25.5} \mathrm{Fe}_{12.5}$ melt spun ribbon. Mater. Charact. 2016, 117, 127-133. [CrossRef]

9. Beeli, C.; Ishimasa, T.; Nissen, H.U. Orientation relation between icosahedral and crystalline phases in Al-Mn alloys. Philos. Mag. B 1988, 57, 599-608. [CrossRef]

10. Ohashi, T.; Fukatsu, N.; Asai, K. Crystallization and precipitation structures of quasicrystalline phase in rapidly solidified Al-Mn-X ternary alloys. J. Mater. Sci. 1989, 24, 3717-3724. [CrossRef]

11. Yamasaki, M.; Nagaishi, Y.; Kawamura, Y. Inhibition of Al grain coarsening by quasicrystalline icosahedral phase in the rapidly solidified powder metallurgy Al-Fe-Ti-Cr. Scr. Mater. 2007, 56, 785-788. [CrossRef]

12. Chlupova, A.; Chlup, Z.; Kruml, T. Fatigue properties and microstructure of quasicrystalline AlFeCrTi alloy. Int. J. Fatigue 2016, 91, 251-256. [CrossRef]

13. Pedrazzini, S.; Galano, M.; Audebert, F.; Smith, G.D.W. Elevated Temperature Mechanical Behaviour of Nanoquasicrystalline $\mathrm{Al}_{93} \mathrm{Fe}_{3} \mathrm{Cr}_{2} \mathrm{Ti}_{2}$ Alloy and Composites. Mater. Sci. Eng. A 2017. [CrossRef]

14. Stan-Głowińska, K.; Lityńska-Dobrzyńska, L.; Kania, B.; Dutkiewicz, J.; Rogal, Ł.; Skuza, W.; Wojewoda-Budka, J.; Gordillo, M.A.; Wiezorek, J.M. Effects of hot-compaction on the structure and properties of Al-Mn-Fe-X alloys strengthened with quasi-crystalline icosahedral phase. Mater. Des. 2017, 126, 162-173. [CrossRef]

15. Davis, J.R. (Ed.) Selection and application of aluminum alloys. In Aluminum and Aluminum Alloys; ASM International: Materials Park, OH, USA, 1993; pp. 59-198. 
16. Chang, H.J.; Fleury, E.; Song, G.S.; Lee, M.H.; Kim, W.T.; Kim, D.H. Microstructure modification and quasicrystalline phase formation in Al-Mn-Si-Be cast alloys. Mater. Sci. Eng. A 2004, 375-377, $992-997$. [CrossRef]

17. Chang, H.J.; Fleury, E.; Song, G.S.; Kim, W.T.; Kim, D.H. Formation of quasicrystalline phases in Al-rich Al-Mn-Be alloys. J. Non-Cryst. Solids 2004, 334-335, 12-16. [CrossRef]

18. Boncina, T.; Markoli, B.; Zupanic, F. Characterization of cast $\mathrm{Al}_{86} \mathrm{Mn}_{3} \mathrm{Be}_{11}$ alloy. J. Microsc. 2009, $233,364-371$. [CrossRef] [PubMed]

19. Song, G.S.; Fleury, E.; Kim, S.H.; Kim, W.T.; Kim, D.H. Enhancement of the quasicrystal forming ability in Al-based alloys by Be-addition. J. Alloys Compd. 2002, 342, 251-255. [CrossRef]

20. Kang, H.; Li, X.; Wang, T.; Liu, D.; Su, Y.; Hu, Z.; Guo, J.; Fua, H. Crystal-quasicrystal transition depending on cooling rates in directionally solidified Al-3Mn-7Be (at.\%) alloy. Intermetallics 2014, 44, 101-105. [CrossRef]

21. Ryan, R.P.; Terry, C.; Leffingwell, S.S.; Beryllium; Ryan, I.R.P.; Terry, C.; Leffingwell, S.S. (Eds.) Toxicology Desk Reference: The Toxic Exposure \& Medical Monitoring Index, 5th ed.; Taylor \& Francis: New York, NY, USA, 1999; pp. 185-190.

22. Inoue, A.; Watanabe, M.; Kimura, H.; Takahashi, F.; Nagata, A.; Masumoto, T. High mechanical strength of qua-sicrystalline phase surrounded by fcc-Al phase in rapidly solidified Al-Mn-Ce alloys. Mater. Trans. JIM 1992, 33, 723-729. [CrossRef]

23. Schurack, F.; Eckert, J.; Schultz, L. Synthesis and mechanical properties of cast quasicrystal-reinforced Al-alloys. Acta Mater. 2001, 49, 1351-1361. [CrossRef]

24. Coury, F.G.; Botta, W.J.; Bolfarini, C.; Kiminami, C.S.; Kaufman, M.J. Reassessment of the effects of Ce on quasicrystal formation and microstructural evolution in rapidly solidified Al-Mn alloys. Acta Mater. 2015, 98, 221-228. [CrossRef]

25. Naglic, I.; Samardzija, Z.; Delijic, K.; Kobe, S.; Dubois, J.M.; Leskovar, B.; Markoli, B. Metastable quasicrystals in Al-Mn alloys containing copper, magnesium and silicon. J. Mater. Sci. 2017, 52, 13657-13668. [CrossRef]

26. Stan-Głowińska, K.; Rogal, L.; Góral, A.; Wierzbicka-Miernik, A.; Wojewoda-Budka, J.; Schell, N.; Lityńska-Dobrzyńska, L. Formation of a quasicrystalline phase in Al-Mn base alloys cast at intermediate cooling rates. J. Mater. Sci. 2017, 52, 7794-7807. [CrossRef]

27. Stan-Głowińska, K.; Lityńska-Dobrzyńska, L.; Rogal, Ł. Influence of Fe addition on the formation of a quasicrystalline phase in bulk Al-rich Al-Mn base alloys. Mater. Charact. 2017, 128, 203-208. [CrossRef]

28. Zhou, W.L.; Li, X.Z.; Kuo, K.H. A new hexagonal metastable phase coexisting with the decagonal quasicrystal in Al-Cr-Ni and Al-Mn-Ni alloys. Scr. Metall. Mater. 1989, 23, 1571-1574. [CrossRef]

29. Van Tendeloo, G.; van Landuyt, J.; Amelinckx, S.; Ranganathan, S. Quasi-crystals and their crystalline homologues in the $\mathrm{Al}_{60} \mathrm{Mn}_{11} \mathrm{Ni}_{4}$ ternary alloy. J. Microsc. 1988, 149, 1-19. [CrossRef]

30. Grushko, B.; Pavlyuchkov, D.; Mi, S.B.; Balanetskyy, S. Ternary phases forming adjacent to $\mathrm{Al}_{3} \mathrm{Mn}-\mathrm{Al}_{4} \mathrm{Mn}$ in Al-Mn-TM (TM = Fe, Co, Ni, Cu, Zn, Pd). J. Alloy Compd. 2016, 677, 148-162. [CrossRef]

31. Khoruzha, V.G.; Kornienko, K.E.; Pavlyuchkov, D.V.; Grushko, B.; Velikanova, T.Y. The Al-Cr-Fe phase diagram. I. phase equilibria at subsolidus temperatures over composition range 58-100 at.\% Al. Powder Metall. Met. Ceram. 2011, 50, 83-97. [CrossRef]

32. Balanetskyy, S.; Pavlyuchkov, D.; Velikanova, T.; Grushko, B. The Al-rich region of the Al-Fe-Mn alloy system. J. Alloy Compd. 2015, 619, 211-220. [CrossRef]

33. Grushko, B.; Mi, S.B. Al-rich region of Al-Cu-Mn. J. Alloy Compd. 2016, 688, 957-963. [CrossRef]

34. Balanetskyy, S.; Meisterernst, G.; Grushko, B.; Feuerbacher, M. The Al-rich region of the Al-Mn-Ni alloy system. Part II. Phase equilibria at $620-1000{ }^{\circ} \mathrm{C}$. J. Alloy Compd. 2011, 50, 3795-3805. [CrossRef]

35. Tsai, A.; Inoue, A.; Masumoto, T. A Stable Quasicrystal in Al-Cu-Fe System. J. Appl. Phys. 1987, 26, L1505. [CrossRef]

36. Gayle, F.; Shapiro, A.J.; Biancaniello, F.S.; Boettinger, W. The Al-Cu-Fe phase diagram: 0 to 25 At. pct Fe and 50. Metall. Mater. Trans. A 1992, 2, 2409-2417. [CrossRef]

37. Zhang, L.; Lück, R. Phase equilibria of the icosahedral Al-Cu-Fe phase. J. Alloy Compd. 2002, 342, 53-56. [CrossRef]

(C) 2018 by the author. Licensee MDPI, Basel, Switzerland. This article is an open access article distributed under the terms and conditions of the Creative Commons Attribution (CC BY) license (http://creativecommons.org/licenses/by/4.0/). 